\title{
Sustainable development and the role of instrumentalism concepts for social institutions and educational system
}

\author{
Tatiana Bilan ${ }^{1}$, Nataliia Lakusha ${ }^{2},{\text { Oksana } \text { Petriv }^{3} \text {, Svitlana Sylkina }}^{4}$. \\ ${ }^{I}$ Candidate of Sciences (Philosophy), Associate Professor of the Department of Cultural Studies and Art \\ Education, Drohobych State Pedagogical University of Ivan Franko, Drohobych, Ukraine \\ ${ }^{2} \mathrm{PhD}$ in Philosophy, Assistant Professor, Assistant Professor of philosophy of Kyiv National \\ University of Construction and Architecture, Kyiv, Ukraine \\ ${ }^{3}$ Candidate of Sciences (Philosophy), Associate Professor of the Department of Cultural Studies and \\ Art Education, Drohobych Ivan Franko State Pedagogical University, Drohobych, Ukraine \\ ${ }^{4}$ Assistant of Department of the Philosophy by Kyiv National University of Construction and \\ Architecture, Kyiv, Ukraine
}

\begin{abstract}
The conception of pragmatism and the educational theory deriving from it are quite popular in management systems and social sciences in the context of the need of implementing sustainable development strategies. This is facilitated, firstly, by the combination in the renewed conceptions of this trend of its bottom-up positions with the ideas of other worldview trends - neo-positivism, existentialism, neoFreudism - which enabled enriching the categorical apparatus and general theoretical content of the educational model, management and social education of pragmatism, while preserving the spirit of the conception. Secondly, the changes undergone by the conception of pragmatism in education have allowed it to successfully integrate into the currently intensified general trend of understanding educational management as a process of socialization of the individual, his/her adaptation to the existing values of Western society. In this context, it is a matter of assessing human behavior not in terms of whether it is consistent with fixed, ,eternale moral principles, but rather in terms of the practical results that human actions contribute to the achievement of a given aim. This aim was understood in different ways: some identified it with the development of personal consciousness, while others linked it to self-improvement or integrity, still others linked it to the ultimate development of all human faculties, etc. Obviously, the very desire for such a shift in the assessment of human behavior reflected the fact that the absolute principles and norms of classical ethics were no longer „,workinge under the new social conditions; a more sophisticated criterion was needed to evaluate behavior in the context of constantly changing factors in social and individual life.
\end{abstract}

\section{Introduction}

One of the few contemporary researchers who focused their close attention on the problems of integration of social sciences, educational philosophy, pedagogy and educational management, and psychology was J. Dewey - the systematizer of the American pragmatism conception, who created its instrumentalist version. It was his philosophical

* Corresponding author: ise.cupw@gmail.com 
and pedagogical, managerial and ethical doctrines that became, as we have already noted, the methodological basis of the conservative trend in the philosophy of education.

"The profound aspects of a person"s spiritual constitution are determined by the way he/she relates to problems of behavior" [1] - noted Dewey, considering philosophical reflection on these problems to be of the utmost importance. Moreover, he broadly understood philosophy as "a general theory of education, the purpose of which is the reconstruction or reorganization of experience which adds to the meaning of experience, and which increases the ability to direct the course of consequent experience" [2]. He saw the main task of the future reconstructed conception as "explaining to people the ideas concerning both the moral and social conflicts of everyday life, and thereby becoming, as far as possible, an instrument for the resolution of these conflicts" [2]. Thus, the conception of education appears to Dewey as a means of restoring, continuing social life.

\section{Research methodology}

The name of Dewey is associated with the philosophical rationale for the progressive development of education and upbringing systems. It was linked, firstly, to his position (along with other philosophers of the late XIX and early XX centuries) on the need to move from the formalism in assessing human behavior that is characteristic of classical ethics to teleology. It referred to an assessment of behavior, not in terms of whether it was consistent with a fixed, "eternal" moral principle, but in terms of the practical results that people es actions contribute to the achievement of a given goal. This goal was understood in different ways: some identified it with the development of consciousness, others with selfimprovement or integrity, others with the ultimate development of all human capacities, etc. Evidently, the very desire for such a shift in the assessment of human behavior reflected the fact that the absolute principles and norms of classical ethics were no longer „working under the new social conditions; a more sophisticated criterion was needed to evaluate behavior in the context of constantly changing factors in social and individual life. However, in its concrete manifestation, this turn marked a shift to a position of subjectivism and relativism.

In implementing it, Dewey could not help but sharply criticize the prevailing formal methods of teaching and education management, the whole structure of secondary and higher education with its characteristic detachment from life, also contributing greatly to his popularity as an advocate of a ,progressive ${ }^{\text {ee }}$ system of upbringing, management and education. Dewey"s popularity also stemmed from the fact that, along with other reformers, he advocated a scientific system of education that relied on the application of the "scientific method" to questions of morality.

What kind of "scientific method" is this? It is part and parcel of pragmatism"s general understanding of science, its methods, which essentially belittled scientific theory. We should recall that, according to Dewey, the method and the means are more important than the aims and results of human actions. Science deals with specific situations or experiences, therefore its laws are devoid of general relevance, they are no more than working hypotheses or tools used in experience. "Theory is the theory of practice ... the construction of action in the mind" [3]. It offers a number of approaches, a number of tools, among which a person must give preference to one in solving the problem. The choice must, however, be based on personal experience, on one's own interest and desire. 


\section{Results of the research}

The process of choosing a theory is not very different from the situation when a carpenter decides to pick up a hammer, a saw or a planer, depending on his or her intention to do something specific. The logical process is also a selection of system elements that are relevant to the case. This individualized selection and adaptation form an integral part of the logic of the situation. Thus, Dewey"s notion of science is reduced to "tools" that are arbitrarily chosen by an individual to adapt them to his or her interests in a particular situation.

From this general view of "scientific theory" raised to a "tool" necessary for the solution of practical problems, Dewey also approaches the understanding of morality as the basis for a theory of education. Similar to any theory, according to Dewey, moral theory is a theory of practice, that is, the idea of what should be done. It consists of the everyday activities of the same ordinary mind that measures manufactory, hammers nails, sells wheat and invents the telephone. "The difference between a childe's idea that $\mathrm{s} /$ he must learn the multiplication table ... and the broadest moral theory is a difference not of a qualitative order, but only in the degree of practice analysis" [2]. However, if the moral theory needs nothing more from it than to be the sum of "the everyday activities of the ordinary mind" and to give a person the skills to profit from his or her actions, then it is hardly tenable to regard it as a scientific theory.

Morality and its theory do not include any stable norms linked to the interests of certain classes. Moreover, Dewey believes that the thesis of the class character of morality and ethics can only serve to destroy society and morals. Various classes create, according to the scholar, their own customs which they use as their own working morality. Each class is firmly convinced of the rightness of their goals and, consequently, is not too scrupulous about the means of achieving them. In the realm of morality, there is no common ground, no mutual understanding, no agreement on the norms of behavior.

Proceeding, however, from this very notion of the essence of moral theory, Dewey creates a new system of ethics. In his view, its novelty, its scientific basis, lies in the fact that it is constructed in the relation to facts, the latter requiring mainly a critical direction of judgement. Gradually their use becomes more customary, and then the social situation takes a certain form or organization: "Similar to the way physical science has led to the organization of the physical world and to the organization of the practical skills of dealing with this world, the ethical theory will cause the organization of the world of social phenomena and the corresponding organization of the mental habits, by means of which the individual associates themselves with this world" [2].

Dewey believes that never before have there been such significant reasons for conflict since each of the conflicting parties found support in their own moral principles. "The mind, which is the only possible anticipator of reconciliation, is in a distant land of abstractions, appearing already after the incident to give an account of the committed facts" [2]. Following Deweyes logic, it is apparent that strong moral norms rooted in real human relations serve as an obstacle to the sustainability of society.

Dewey rejects the existence of ideals, remote goals in the name of which people, the masses of people embark on a path of struggle. He seeks to create a universal ethical system that would serve every individual, irrespective of his or her social position, to achieve his/her individual goal as relevant to a particular situation, his/her personal conception of virtue, justice, equality. Concerning the principles, norms and rules that emerge from social customs, they are, according to Dewey, nothing more than the intellectual tools needed to analyze particular situations. However, these tools by no means perform the function of 
moral norms. Dewey believes that morality requires specific methods of enquiry and invention to create working hypotheses that contribute to the identification of problems and evils. Therefore, "the pragmatist contribution to the logic of individual situations, each with its own indispensable goods and principles, is to shift the attention of theory from the rapture of general concepts to the problem of developing effective research methods" [2].

Dewey rightly emphasizes that before making a decision, a person has to understand a particular situation. A moral situation is always problematic, including a conflict that needs to be resolved. Dewey shifts the center of gravity to the human mind in determining how one looks for a way out of a problematic situation, what he/she relies on in their choices. It is the human mind that is given the function to analyze a situation with its "tools", to establish what is good and what is evil in it, and to work out an appropriate plan of action. Moreover, good and evil are devoid, according to Dewey, of the status of general concepts; they are unique to each situation. In addition, the definition of acts, phenomena like good or evil, depends only on a person's critical judgement about a given situation, about the choices she considers appropriate in a given case, without observing any general patterns. The main thing that characterizes the essence of choice is a possibility, which is identified with desirability.

Dewey does not accidentally replace the notion of historical regularity, necessity, with the notion of opportunity. Out of the multitude of possibilities, a person has the right to choose the one that is prompted by the situation itself and ensures the satisfaction of his/her desires and the obtaining of benefits. Any action in accordance with necessity, with the laws of the development of objective reality, Dewey regards as a manifestation of fatalism, a denial of the individual's freedom. However, any choice that is made without reliance on conscious necessity becomes arbitrary and, in the end, blind subordination to necessity.

In an attempt to disguise the voluntaristic character of his position, Dewey concretizes it by specifying that a choice made on the basis of desire or taste alone has no moral value since there is a difference between what a person wants and what is objectively better, between what satisfies a person and what is satisfactory. But in formulating a criterion for this distinction, Dewey again blatantly takes the position of voluntarism. It appears that the right direction of our desires and tastes cannot be provided by the analysis of their objective content. Only an individual's critical judgement of the conditions and results of experience can direct the individual's desires and interests from the right path. "The interest must not only induce the individual to judge, but must compel him/her to judge critically, using all the resources at his/her disposal, which can provide the greatest probability of truthfulness of the conclusion" [4]. The reasons for the wrong choices, the wrong behavior of an individual, Dewey searches for in his/her mental inclinations, which have influenced the nature of her judgement. In other words, no objective circumstances stipulate personal behavior, it is a product only of his/ her own Self.

Consequently, human behavior, according to Dewey, lacks a sustainable higher purpose, firm principles, norms that should have been taken into account in the choice of one"s actions. A person has only a situation in front of her/him and the possibilities invested in it, one of which she/he prefers according to her/his desires and interests. And the latter largely depend, as already noted, on his/her mental state. These are the methodological guidelines that Dewey relied on in creating his philosophical pedagogical theory of education.

The conception of pragmatism and the educational theory arising from it lost its popularity in the 1960s. However, by the 1970s their resurgence in a somewhat modernized form was again noticeable. This was facilitated, firstly, by the combination in the renewed conceptions of this trend of its bottom-up positions with the ideas of other worldview trends - neo-positivism, existentialism, neo-Freudism, which enabled enriching the categorical apparatus and general theoretical content of the educational model, management and social 
education of pragmatism, while preserving the spirit of the conception formulated by Dewey. Secondly, the changes undergone by the conception of pragmatism in education have allowed it to successfully integrate into the currently intensified general trend of understanding educational management as a process of socialization of the individual, his/her adaptation to the existing values of Western society.

Deweyes methodological approaches to education in the modern context are supported by a group of theorists headed by A. Maslow, A. Combs, E. Kelly, C. Rogers, T. Brameld, S. Hook and others. They support Dewey's provision on the role of education in society, namely that the value of education depends on the extent to which it contributes to individual growth, helps individuals to find answers to everyday problems that arise, and most importantly, indicates how to better adapt to a given situation, to survive in it, since life is "primarily a constant process of adjustment, not only biological, but also social" [5].

Proponents of the neopragmatist conception of education, upbringing and management reinforce the individualistic orientation of Dewey's ideas and his anti-intellectualism, converging in many respects with the concept of pragmatism and existentialism. Following Dewey, they assume that a person's attributes, abilities, talents are of innate nature, that the basis of his/her creativity is embedded in the depths of the human Self, even the desire for self-control (self-management) is also innate. Therefore, as A. Maslow points out, human nature is documentary and usually not subject to significant change [6]. It is no coincidence, therefore, that he adopts a sharply negative attitude towards the conscious part of the Self, which is given the function of controlling human actions, self-criticism.

The education system, according to neopragmatism, is designed to reveal the essence of innate human nature and to rely on it. Moral education, as its most important part, emerges, according to Maslow, from a hierarchy of innate human needs - starting with such basic needs as food, procreation, to such high needs as personal self-actualization.

As we can see, following Dewey, his successors recognize that the abilities inherent in human nature must have a chance to manifest themselves, and that the education system is supposed to facilitate this. However, while Dewey linked the possibility of the manifestation and growth of human abilities to the degree of socialization and sought to subordinate education to the interests of democracy, the neopragmatists, like the existentialists, maintain that human behavior is entirely self-determined, that each individual is his/her own project, creating himself/herself in the process of free choice. Maslow writes: "The sources of growth and humanity of the individual are in the individual himself/herself; they are by no means created by society. The latter can only help or hinder the growth of a person's humanity, just as a gardener can help or hinder the growth of a rosebush, but he cannot determine that an oak tree will grow instead of a rosebush" [7]. Although Maslow recognizes the importance of culture, language, abstract thinking, moral qualities (especially the ability to love another person) for the development of the individual, he concludes that the actualization of the individual (that is, the fullest expression of all his/her capacities and abilities) is only related to his/her inner world, since only the individual him/herself knows what is good for him/her, for good cannot be defined, confirmed by reference to objective facts, it can only be felt; good is something that arouses satisfaction in the individual.

Naturally, goodness is associated with a sense of pleasure, but the basis for this feeling is the objective content of actions that have a favorable effect not only on those who have committed them but also on other people, optimally, on the entire society. At the same time, the deeds have to conform to the criterion of morality, i.e., to contribute objectively to the development of a person and society. If, following Maslow, one connects goodness only with a felt sense of satisfaction, then one cannot assess the real moral meaning of one es deeds. 
According to the neopragmatists, just as cognition is an individuales own formation of his/her worldview independent of objective laws, human behavior is only a self-expression, free from any principles, social relations, norms of morality, etc. A person does not need to constantly model their behavior on their relationships with the people around them, to adapt to them by hiding something innermost from them, or to deceive them, since all their actions are motivated by the value of their Self.

Extending this idea, A. Combs argues that what matters most in shaping a person "s behavior is finding out how he or she perceives the Self and the world around him or her. If he or she is self-confident, there is no reason to worry about the nature of the values he/she is guided by [8]. Therefore, self-satisfaction with oneself, with one's actions and perceptions, self-confidence serves as the only guarantee of one's positive outlook on the world. It turns out that a person does not need to know the true meaning of events, to judge the behavior of other people by their specific actions, it is sufficient for a person to be in a good mood, to be satisfied with one's position and behavior in order to perceive all surrounding people and events appropriately.

It is obvious that neopragmatists form to a certain extent a somewhat uncritical, thoughtless attitude of the individual to life, ultimately serving to preserve the stability of the existing system. Characteristic in this regard is A. Combs' statement that a person who feels satisfied is capable of friendship with all people, including those who are antagonistic to him/her [9]. Moreover, Combs, conditioning all individual behavior on a sense of satisfaction, justifies the facts of avoidance of any action and decisions prompted by the environment. Similar to Dewey, Combs opposes "lofty goals". He believes that people who know themselves well, their desires, always set themselves quite realistic, easily achievable goals. And this, in turn, generates positive emotions in the individual and lays the foundation for a good moral state. Combs preaches tolerance for uncertainty, praising people who "find it possible to live comfortably with unresolved problems" [4].

In other words, he openly encourages people to be conformist, attaching a positive moral sense to this kind of behavior. In Combs ${ }^{\text {ee }}$ view, people inclined towards conformism have a very realistic view of the purpose of their actions, choosing the one that best suits their abilities. And this is the basis of an individual's success and good morale. This means that upbringing must not in any way shape a person to change his or her social status. It is mainly meant to teach a person to feel happy at the level of social position he/she occupies by the will of circumstances, to teach him/her to be guided in life only by her own sense of self. To make a person feel satisfied everywhere and anywhere is the main aim of upbringing, which is not, when considered carefully, without a certain social grounding.

Behavior that relies not on the knowledge of the objective content of the situation, but only on a person "s own perception of it, is essentially relativistic in nature, there is nothing sustainable about it, it is subject only to momentary interests. "The stimulus that guides a person "s choice grows from the moment and cannot be foreseen by anyone in advance", argues C. Rogers [10]. It is impossible to predict the outcome of behavior, which is a consequence of the immediate situation and therefore cannot be linked to distant goals. "A person", argues Kelly, "must seek a firm foundation for his/her future. One thing that he/she can be sure of when it comes to prospects is that tomorrow will be different from today" [11].

A person needs to find the premises for his/her actions outside themselves, by their own reflections and assessments. The surrounding people, their opinions, social norms and principles can serve as a basis for his/her choices, because their function is to control, to criticize the behavior of the individual, and therefore they can only hinder his/her selfexpression, his/her growth. In other words, neopragmatists advocate solidarity in the actions and evaluations of the individual. Moreover, they see this kind of behavior as a 
source of activity and optimism, since the individual is not bound by anything and is guided only by his/her desires and will.

\section{Conclusions}

The desire to predict the future, the realization of which is beyond a person "s reach, cannot only constrain his/her action because a person"s activity will be infused with the hope of improvement.

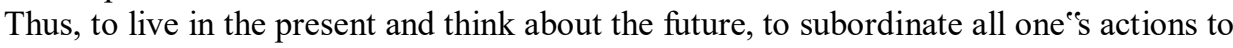
a sense of satisfaction by reflecting on the present basis of this feeling - this is the basic credo of the neopragmatist educational conception, which regardless of the subjective desire of its proponents, can be used to justify the morality of permissiveness.

Developing the ideas of the conception, modern representatives of the neopragmatist conception of human development which has incorporated some ideas of existentialism argue that personal self-expression is not achieved by the mind but only by the senses, that a person "s behavior is a product of the perception of certain phenomena at the moment of action. Therefore, the individual directs his/her own behavior with the help of those data which he/she has discovered through direct sensory experience. Hence, it follows that the nature of a person"s behavior, of the acts he or she has committed, is determined not by their objective content, but by the purpose to which they have been subjected and not by the consequences to which they lead, but by how the phenomena, the circumstances from which he/she emerges in their acts, and the people to whom they are related, are represented to the person. In other words, neopragmatists attach importance to the self-evaluation of behavior, including its evaluation by others, by society.

The task of institutions of higher and secondary education is to pay more attention to the unique experience of students, shaping their individuality by using, as far as possible, all disciplines of the curriculum in the process of learning. The school should serve as a laboratory for discovering the unique Self of each student because only then he or she will have the opportunity to learn about the world around them.

It is necessary to know what the result of any mental predisposition of a person is, its influence on the outlook and then on behavior. By clarifying the social situation, being aware of the motives for one's actions and their consequences, one constructs general statements in which his/her experience is expressed, connections between the circumstances. These provisions are used and applied to solve certain problems in the future.

\section{References}

1. J. Dewey, Introduction to the Philosophy of Education (Publishing House, Moscow, 1999)

2. J. Dewey, Democracy and Education (The Free Press, Macmillan Company, New York, 1966)

3. J. Dewey, Democracy and Education. (Litopys, Lviv, 2003)

4. A. Combs, Humanism, Education and Future (Educational Leadership, Boston, 2017)

5. N. Talent, Psychology of Adjustment (Routledge, N.-Y, 2019)

6. A. Maslow, in Perceiving, Behaving, Becom. A New Focus Educ. (Assn for Supervision \& Curriculum, 1982), p. 127

7. A. H. Maslow, Motivation and Personality (HarperCollins Publishers, Scotland, 2017)

8. A. W. Combs, A. B. Miser, and K. S. Whitaker, On Becoming a School Leader: A Person-Centered Challenge (Association for Supervision \& Curriculum Deve ., 
Washington, DC, 2019)

9. A. W. Combs, Personal Approach to Teaching: Beliefs That Make a Difference (Allyn \& Bacon, Boston, 2012)

10. C. R. Rogers, in Perceiving, Behaving, Becom. A New Focus Educ. Yearb. Ed. A. W. Combs (Edited by A. W. Combs) (Association for Supervision and Curriculum Development, Washington, DC, 2012), p. 256

11. E. Kelly, in Perceiving, Behaving, Becom. A New Focus Educ. (Assn for Supervision \& Curriculum, 2012), p. 127 